\title{
Helpful or harmful? How frequent repetition affects perceived statement credibility
}

\author{
Koch, Thomas ; Zerback, Thomas
}

\begin{abstract}
On the basis of experimental data, we study how repetition of a statement affects perceived statement credibility. We identify 2 counteracting effects: The first effect, known as "truth effect," describes a positive relationship between repetition and statement credibility. People tend to ascribe higher credibility to messages that they repeatedly encounter. In contrast, the second effect occurs when repetition is taken too far. Here, an indirect and negative effect is identified and participants start to perceive the message as a persuasive attempt. This perception triggers reactance, which in turn considerably reduces participants' trust in the source and leads to a significant decrease in the overall credibility of the message. Our results broaden the understanding of the benefits and harms of repeated persuasive messages.
\end{abstract}

DOI: https://doi.org/10.1111/jcom.12063

Posted at the Zurich Open Repository and Archive, University of Zurich ZORA URL: https://doi.org/10.5167/uzh-203968

Journal Article

Accepted Version

Originally published at:

Koch, Thomas; Zerback, Thomas (2013). Helpful or harmful? How frequent repetition affects perceived statement credibility. Journal of Communication, 63(6):993-1010.

DOI: https://doi.org/10.1111/jcom.12063 


\author{
Helpful or Harmful? \\ How Frequent Repetition Affects Perceived Statement Credibility
}

Thomas Koch and Thomas Zerback

Ludwig-Maximilians-University Munich

\title{
Author Note
}

Thomas Koch, Department of Communication Science and Media Research, LudwigMaximilians-University Munich.

Thomas Zerback, Department of Communication Science and Media Research, Ludwig-Maximilians-University Munich.

Correspondence concerning this article should be addressed to Thomas Koch, Department of Communication Science and Media Research, Ludwig-MaximiliansUniversity, Oettingenstraße 67, 80538 Munich. E-mail: Koch@ifkw.lmu.de 


\begin{abstract}
Based on experimental data, we study how repetition of a statement affects perceived statement credibility. We identify two counteracting effects: The first effect, known as "truth effect", describes a positive relationship between repetition and statement credibility. People tend to ascribe higher credibility to messages that they repeatedly encounter. In contrast, the second effect occurs when repetition is taken too far. Here, an indirect and negative effect is identified and participants start to perceive the message as a persuasive attempt. This perception triggers reactance, which in turn, considerably reduces participants' trust in the source and leads to a significant decrease in the overall credibility of the message. Our results broaden the understanding of the benefits and harms of repeated persuasive messages.
\end{abstract}

Keywords: truth effect, repetition, persuasion, reactance, credibility, persuasive intent 


\section{Helpful or Harmful? How Frequent Repetition Affects Perceived Statement Credibility}

Frequent repetition of persuasive messages is a common strategy to create attention for and convince others of one's arguments. Nonetheless, the "effects of repeated exposure to persuasive communications [is] an area that has generated surprisingly little research by social psychologists despite its frequent occurrence in and importance to everyday life“ (Cacioppo \& Petty, 1979, p. 97). Although Cacioppo's and Petty's conclusion dates back more than 30 years, we still do not know much about the persuasive effects of message repetition. Research so far has mainly focused on repetition effects on attitudes (Zajonc 1968; Bornstein, 1989) and credibility (Hasher, Goldstein, \& Toppino, 1977; Dechêne, Stahl, Hansen, \& Wänke, 2010). In both cases, positive relationships have been observed: Repeating persuasive messages yields more favorable attitudes and increases credibility. However, repetition may also have negative effects, if it exceeds a certain threshold, resulting in an inverted U-shaped relationship. Although this pattern has been observed in several studies (e.g. Cacioppo \& Petty, 1979; Saegert \& Jellison, 1970; Zajonc, Shaver, Tavris, \& Van Kreveld, 1972), there is still a lack of research explaining its causes, especially regarding persuasive stimuli.

In the present article, we examine the impact of multiple repetitions of persuasive messages on statement credibility and expect two counteracting effects. For one, we assume a direct, positive effect of repetition on statement credibility: Recipients often have to rely on heuristics when assessing whether a message is true or not and consider whether the respective statement appears familiar (Arkes, Boehm, \& Xu, 1991; Arkes, Hackett, \& Boehm, 1989; Parks \& Toth, 2006; Reber \& Schwarz, 1999; Roggeveen \& Johar, 2002). This familiarity heuristic occurs unconsciously and is influenced by the frequency of a statement being perceived: Repetition increases familiarity and leads to the (false) assumption of having heard the statement in a different context before, which subsequently enhances belief in the statement (Hasher et al., 1977). In cognitive psychology this process is known as the "truth 
effect" and has been empirically confirmed under various experimental conditions and therefore can be considered a stable phenomenon (Dechêne et al., 2010).

Secondly, we assume that repetition triggers an indirect and negative effect causing a decrease of statement credibility: Repeating a statement might be interpreted as a persuasive attempt, which could evoke reactance (Moyer-Gusé, Jain, \& Chung, 2012). Reactance in turn might exert a negative effect on source credibility and therefore may lead to lower levels of statement credibility. Hence, we expect two contradictory effects of statement repetition: a direct increase of statement credibility (truth effect), and an indirect decrease of credibility evoked by reactance.

\section{Increased credibility of statements through repetition: The truth effect}

The repeated perception of a statement increases a person's subjective impression that the statement is true (Hasher et al., 1977). This is due to two different processes: First, recipients misattribute the source of the statement. Repeated perception leads recipients to mistakenly believe that they have heard the statement before from different sources (Arkes et al., 1991; Arkes et al., 1989; Roggeveen \& Johar, 2002; Schwartz, 1982). Over the course of socialization, people learn to more readily believe statements which originate from numerous independent sources (Arkes et al., 1991; Brown \& Nix, 1996). These 'other' sources are considered to be validating points of reference, enhancing statement credibility.

The second process is based on repetition induced familiarity with the statement itself. The repeated encounter of a stimulus increases its "processing fluency": The information can be processed more easily with every additional perception (Bornstein, 1989; Reber, Winkielman, \& Schwarz, 1998; Seamon et al., 1995). Enhanced processing fluency leads to a feeling of familiarity: People consider statements which are, for instance, easier to read (e.g., due to color contrast or large font sizes) to be more familiar and, in turn, more credible as compared to statements which are more difficult to read (Reber \& Schwarz, 1999; Unkelbach, 
2007). The feeling of familiarity finally leads to higher subjectively perceived statement credibility (e.g. Parks \& Toth, 2006; Reber \& Schwarz, 1999; Unkelbach, 2007; Unkelbach, Bayer, Alves, Koch, \& Stahl, 2011).

The magnitude of the truth effect depends on several factors, such as recipient characteristics. Prior knowledge about the specific subject is of particular importance: The truth effect is weaker or absent when recipients are confronted with statements about which they have no prior knowledge (Arkes et al., 1989; Boehm, 1994; Koch \& Zerback, 2012). Furthermore, involvement moderates the truth effect (Begg, Anas, \& Farinacci, 1992; Begg, Armour, \& Kerr, 1985; Hawkins \& Hoch, 1992). Low levels of involvement lead to an increase in the strength of the truth effect (c.f. the metaanalysis of Dechêne et al., 2010), whereas a minimum or baseline level of involvement is required to evoke it (Hawkins \& Hoch, 1992, p. 222).

In addition to recipient characteristics, specific stimulus characteristics influence the strength of the truth effect. It weakens and even diminishes if the answer to the respective statement is too obvious. For example, people will not accept a statement like, "The earth is flat", even if it is repeated several times (Roggeveen \& Johar, 2002). Accordingly, the truth effect is strongest when participants are uncertain about a statement's validity (Unkelbach, 2007). However, the time lapse between repetitions plays a negligible role regarding the strength of the truth effect; it appears to make little difference whether minutes (Begg \& Armour, 1991; Hawkins, Hoch, \& Meyers-Levy, 2001; Koch \& Zerback, 2012; Schwartz, 1982), or even weeks (Bacon, 1979; Gigerenzer, 1984; Hasher et al., 1977) have elapsed between statement repetitions. In fact, the effect does not diminish before three weeks have passed after the last exposure (Arkes et al., 1991). The occurrence of the truth effect also appears to be independent of statement type; it has been observed in various domains, such as factual knowledge statements (e.g., Bacon, 1979; Schwartz, 1982), advertising slogans (e.g., Hawkins et al., 2001; Johar \& Roggeveen, 2007; Roggeveen \& Johar, 2002), and expression 
of opinions (Arkes et al., 1989). In addition, it occurs regardless of how a statement is presented, be it, for instance, a graphical (Hawkins \& Hoch, 1992) or oral presentation (Gigerenzer, 1984; Hasher et al., 1977). Although most studies in the truth effect have been conducted in the laboratory, it has also been observed in natural settings (Boehm, 1994).

The focus of the present study is on the number of presentations of a given statement. Most studies repeat the respective statement just once or twice. Yet only few studies have analyzed how a high frequency of presentations affects the assessment of a statement's perceived validity. Hasher et al. (1977) presented slogans three times and observed only a slight increase in perceived credibility ${ }^{1}$ after the last measurement. A similar pattern was also observed by Gigerenzer (1984). Arkes et al. (1991) tested the effect with a total of six presentations of the same statement. Again, a significant increase in perceived credibility was observed only between the first and the second measurement. Yet, in all studies mentioned above, at least one week had passed between the presentations of the statement. So the question remains what would happen to the truth effect if the time lapses between the statements were shorter? Hawkins et al. (2001) presented a statement (here: an advertising claim) four times within one hour. Credibility increased considerably after the first repetition and only marginally after subsequent repetitions, leading the authors to conclude that "the biggest boost comes from one prior exposure" (Hawkins et al., 2001, p. 9). Koch and Zerback (2012) used six presentations within only a few minutes and found that credibility increased until the third presentation, whereas repeating a statement six times weakened the effect.

In conclusion, previous research shows that after the third or fourth statement presentation, the truth effect either weakens or no longer occurs at all. How can these effects of frequent presentation of the same message be explained theoretically? There are several models focusing on the effects of repetition of persuasive communication on attitude change (e.g. Berlyne, 1970; Cacioppo \& Petty, 1979, 1989). Fink and Cai (2013) e.g. discuss in their discrepancy models of belief change assumptions and implications for message repetition on 
belief positions (see also Kaplowitz, Fink, Armstrong, \& Bauer, 1986). Depending on the number of repetitions and "the ratio of the change achieved by a message [...] to the change advocated by the message", the authors discuss various effects (Fink \& Cai, 2013, p. 88). According to the discrepancy model, repetition causes recipients either (1) to move successively toward the position advocated or (2) the belief position oscillates due to message repetition with damping alternately overshooting and undershooting the position advocated or (3) message repetition causes the belief positions to move increasingly away from the position advocated (p. 87-88). Yet, the discrepancy model focuses in particular on belief-position dimensions and not on the psychological processes that might cause a decline in statement credibility.

Koch and Zerback (2012) argue that presenting a statement too often may evoke reactance working against the truth effect. Likewise, Miller (1976) suspects that presenting statements too frequently triggers reactance. He demonstrated that moderate exposure to posters with political slogans enhanced participants' attitudes towards the message, whereas overexposure dampened positive attitudinal effects. Although both studies explain their findings in terms of reactance, reactance itself was not measured. The authors' conclusions regarding reactance are, therefore, post hoc interpretations. To date, the extent to which reactance counteracts the truth effect remains unclear, both from theoretical and empirical perspectives.

\section{Decreased credibility of statements through repetition}

The previous paragraphs show that multiple repetition of a statement can reduce its credibility - but what are the processes underlying this effect? We assume that recipients interpret frequent repetition as a persuasive tactic and thus as a persuasive attempt. Friestad and Wright (1994) refer to this process as activation of persuasion knowledge, which means knowledge of persuasive strategies as well as intentions. Recipients have gained this kind of 
knowledge in the course of their socialization (Friestad \& Wright, 1994). Whether or not people recognize the persuasive intent depends on various factors. For example, recipients are more likely to recognize a persuasive attempt when they are attentive and have sufficient cognitive resources available (Campbell \& Kirmani, 2000; Williams, Fitzsimons, \& Block, 2004), when the communicator's persuasive intention is explicitly communicated, or when they are forewarned by contextual information (McGuire \& Papageorgis, 1962; Petty \& Cacioppo, 1977). In addition, whether recipients perceive a persuasive intent is influenced by stimulus characteristics: The more conspicuous the persuasive character of the stimulus, the more likely it will be identified as an attempt at persuasion (concerning brand placements, e.g. Cowley \& Barron, 2008; Matthes, Schemer, \& Wirth, 2007; Schemer, Matthes, Wirth, \& Textor, 2008). Recipients recognize an attempt at persuasion for example when "messages [...] create the perception, that the source was trying 'too hard' to sell his case, make only one side of the issue salient, create the perception of extreme bias on the part of the source" (Smith, 1977, p. 198). It is precisely these associations with persuasive intents that a high frequency of statement repetition should generate. A very high repetition frequency might draw recipients' attention to the persuasive intent of the communicator. From a certain point on, repetition is not disregarded or dismissed as merely incidental, but rather identified as a persuasive tactic, which leads to $\mathrm{H} 1$ : There is a positive relationship between the number of presentations of a statement and the perceived intent to persuade.

Identifying persuasive intentions has a range of consequences. In the course of socialization, recipients not only learn to recognize persuasive attempts, but also how to deal with them; these are typically characterized as defensive reactions (Friestad \& Wright, 1994). J. W. Brehm $(1966 ; 1972)$ argues that the identification of an attempt at persuasion is perceived as a threat to freedom (cf. also Kohn \& Barnes, 1977; Reinhart, Marshall, Feeley, \& Tutzauer, 2007; Worchel \& Brehm, 1970). When individuals experience barriers and constraints that restrict their freedom, they become uncomfortable and react aversively 
(Burgoon, Alvaro, Grandpre, \& Voulodakis, 2002; Wicklund, 1974) since they do not want to be forced to choose a certain alternative. If a person's freedom is threatened, restricted, or lost, the person wishes to restore it; this motivation is known as reactance (J. W. Brehm, 1966; S. S. Brehm \& Brehm, 1981). Moyer-Gusé and Nabi (2010) as well as Moyer-Gusé et al. (2012) demonstrate that recognizing persuasive intentions triggers reactance. In line with these theoretical and empirical findings, we also maintain that the recognition of an attempt at persuasion results in increasing reactance: There is a positive relationship between a perceived intent to persuade and the recipient's reactance $(\mathrm{H} 2)$.

Reactance has various consequences, which can be differentiated into behavioral and subjective effects (J. W. Brehm, 1972; S. S. Brehm \& Brehm, 1981). Behavioral effects are manifested in either direct or indirect restoration of the threatened or revoked freedom. Direct restoration takes place, for instance, when an alternative is chosen even if it is obstructed or revoked; indirect restoration means that an individual performs a related behavior to the threat (J. W. Brehm, 1966, p. 10). In this study, we do not focus on the effects of statement repetition on behavior, but on the subjective effects caused by reactance (J. W. Brehm, 1972; S. S. Brehm \& Brehm, 1981). Reactance can negatively affect the perception of the communicated content (LaVail, Anker, Reinhart, \& Feeley, 2010; Meirick \& Nisbett, 2011). When recipients show reactance, they often strengthen an attitude contrary to the intention of the communicator (S. S. Brehm \& Brehm, 1981). Besides its negative effects on the perception of the communicated content, reactance also affects source perception (Meirick \& Nisbett, 2011; Quick \& Bates, 2010). In this respect, studies especially observe negative effects on source credibility (Grandpre, Alvaro, Burgoon, Miller, \& Hall, 2003; C. H. Miller, Lane, Deatrick, Young, \& Potts, 2007; Quick \& Bates, 2010). We therefore assume that increasing reactance results in a decrease in the perceived message credibility (H3a) as well as source credibility $(\mathrm{H} 3 \mathrm{~b})$. 
Ultimately, the perceived credibility of the communicator affects, in turn, the perceived credibility of his or her message (Begg et al., 1992). Numerous studies have shown that credible communicators have a greater influence on attitudes than communicators who are less credible (Hovland, Janis, \& Kelley, 1953; Hovland \& Weiss, 1951). Accordingly, we expect a positive relationship between a communicator's perceived credibility and the statement's credibility (H4).

The relationships described in the previous paragraphs between a) the number of statement repetitions, b) perceived intent to persuade, c) reactance, d) trust in the communicator, and e) statement credibility, constitute a complex interdependency, as depicted in Figure $1(\mathrm{H} 1-\mathrm{H} 4)$. First we expect an indirect negative effect of repetition on statement credibility. The result of increasing repetition frequency should be that recipients become aware of the attempt at persuasion and develop reactance, in turn leading to a reduction in the overall credibility of the statement (directly, or indirectly due to the communicator's decreasing credibility).

These expected effects stand, however, in opposition to the truth effect, according to which recipients are more likely to believe a statement that is repeatedly presented to them (Dechêne et al., 2010; Hasher et al., 1977). Thus finally, we expect a positive relationship between the number of statement presentations and its perceived credibility (H5). To conclude, statement repetition should lead to two simultaneously occurring, but contradictory effects: To a direct increase of statement credibility (truth effect), as well as to an indirect decrease of credibility evoked by reactance.

\section{Figure 1}

Theoretically postulated relationships between statement repetition frequency and statement credibility 


\section{Method}

\section{Participants}

We conducted an experiment to test our hypotheses with volunteers recruited in seminars and lectures. Altogether, 167 subjects participated in the study (115 female, 52 male). The average age was 26.41 years $(S D=9.17) ; 87 \%$ of the participants had achieved a higher education entrance qualification. Participants were randomly assigned to one of five groups, which did not significantly differ in terms of gender, $\chi^{2}(4, N=167)=0.44, p=.98$, age, $F(4,161)=1.83, p=.18$, and education, $\chi^{2}(8, N=167)=7.58, p=.48$.

\section{Stimulus}

Participants read a newspaper article of about 600 words in length. On average, it took just less than three minutes to complete reading (median, 196 seconds). The first paragraph explained the principle of microcredit loans (in the amount of approximately 100-200 dollars) that are given to poorer population segments of emerging nations, serving as start-up capital for microenterprises. The second section of the article consisted of an interview with Muhammad Yunus, who is considered to be the founder of the microcredit loan system. We used a shortened version of an original interview. Participants were told that the purpose of the study was to evaluate the quality of the interview; after the survey, participants were debriefed and provided with the link to the original article.

The number of presentations of the statement that 'microcredits reduced poverty in emerging nations' served as our independent variable. We produced five versions of the interview, which were identical except for message frequency. The control group (CG) did not receive the statement. The experimental groups read it either once (EG1), three (EG2), five (EG3), or seven times (EG4). The wording of the statement was slightly modified in each version in order to appear more authentic (e.g. "And it turns out that microcredit loans have 
already significantly decreased poverty in emerging nations"; "Still, in emerging nations, microcredit loans have already reduced poverty considerably"). Such minor variations in the wording are not uncommon when invoking the truth effect (Arkes et al., 1991; Begg et al., 1985).

\section{Measures}

\section{Statement credibility}

We measured participants' assessments of statement credibility by asking (on a 5point Likert scale) whether they believe the following three claims to be right or wrong: "Microcredit loans have reduced poverty in emerging nations", "Microcredit loans have considerably decreased poverty in emerging nations", "Microcredit loans have markedly reduced poverty in emerging nations" $(\alpha=.92, M=2.54, S D=0.91)$. To distract respondents, we mixed these three items with buffer items that referred to attitudes towards microcredit and development aid and distributed all questions randomly across two sets.

\section{Perceived intent to persuade}

Using the following two items, we checked whether the participants realized that they were exposed to an attempt at persuasion (5-point Likert scale): "I had the feeling that Mr. Yunus wanted to convince the reader of his standpoint"; and "Mr. Yunus wanted to convince me of his views" $(\alpha=.88, M=3.95, S D=0.98)$.

\section{Reactance}

To measure reactance, we relied on the one-dimensional reactance scale developed by Herzberg (2002). We only used items that we considered relevant to our design, as the general disposition to reactance was not of interest. The three selected items (again, on a 5-point Likert scale) were: "Mr. Yunus tried to restrict my personal freedom of choice"; "It bothers 
me that Mr. Yunus presented himself as a role model"; and "I would really like to disagree with Mr. Yunus" $(\alpha=.79, M=2.23, S D=0.96)$.

\section{Communicator credibility}

Finally, we examined perceived source credibility by using items that ask for perceived expertise and trustworthiness (Hovland et al., 1953; Hovland \& Weiss, 1951). ${ }^{2}$ Expertise refers to the communicator's ability to make valid statements about a particular topic, whereas trustworthiness refers to the "degree of confidence in the communicator's intent to communicate the assertions he considers most valid" (Hovland et al., 1953, p. 21). We used a semantic differential (5-point scale), that included four pairs of adjectives: dishonest-honest, untrustworthy-trustworthy, qualified-unqualified and insincere-sincere $(\alpha$ $=.86, M=3.53, S D=0.84)$.

\section{Findings}

Testing our hypotheses poses particularly demanding requirements for the chosen method of analysis. On the one hand, the method must be able to mathematically distinguish both direct and indirect effects of the independent variable. On the other hand, the relationships in question should not only be established between observable variables, but also between constructs (latent variables). ${ }^{3}$ For this reason, we used a linear structural equation model that fulfills both criteria (Cheung \& Lau, 2008; Holbert \& Stephenson, 2003). Zeroorder correlations of all constructs included in the model are presented in Table 1. Figure 2 shows the relationships between the five constructs found on the basis of our experimental data.

Table 1

Zero-Order Correlations 
Figure 2

Observed Structural Equation Model

The empirical data confirm the theoretically hypothesized relationships between the individual variables. The model presented in figure 2 reveals an acceptable overall model fit (Holbert \& Stephenson, 2002; Hu \& Bentler, 1999): $\chi^{2}=72.95, d f=50, p=.02 ; \mathrm{SRMR}=.08$; RMSEA $=.05 ; \mathrm{CFI}=.98 .^{4}$ All calculations were performed using Mplus software.

With a single exception (see below), all standardized path coefficients are statistically significant $^{5}$ and point in the expected direction, supporting the validity of our theoretical assumptions. Presenting a statement more often does significantly increase the probability that participants identify the stimulus material as an attempt to persuade ${ }^{6}, \beta=.29, p<.001$. This confirms $\mathrm{H} 1$ and, in theoretical terms, fulfills the first key requirement for the simultaneously occurring indirect effect of repetition. In addition, it is important to determine whether a perceived attempt at persuasion leads to reactance on the part of the recipients. This relationship is also confirmed by the data, $\beta=.38, p<.001$. We therefore see $\mathrm{H} 2$ confirmed as well. We further assumed that reactance should lead to a loss of trust in the communicator (H3b) and should also directly affect the assessment of the statement itself (H3a). However, reactance does not exert a significant negative effect on statement credibility, $\beta=-.10, p=$ .43. $\mathrm{H} 3 \mathrm{a}$ is therefore rejected. However, reactance negatively influences communicator credibility, $\beta=-.71, p<.001$, which confirms H3b. Finally, the indirect path is completed by a strong correlation between communicator credibility and statement credibility, $\beta=.51, p<$ .001 . The more credibility participants ascribe to the communicator, the more likely they are to believe that microcredit loans have reduced poverty in emerging nations. Thus, $\mathrm{H} 4$ is also confirmed.

In addition to the indirect ramifications, repetition frequency also yields a positive effect on perceived statement credibility, $\beta=.17, p<.05$. This is in line with earlier findings 
on the truth effect, as well as with H5. The more often a person reads the statement "microcredit has reduced poverty in emerging nations" in the newspaper article, the more likely he or she believes it.

The evidence of a positive direct effect and a negative indirect effect raises the question which of the two would ultimately predominate. The model clearly depicts the direct effects of repetition, expressed by the coefficient of the path from repetition to statement credibility, $\beta_{\mathrm{dir}}=.17, p<.05$. The indirect effect, however, has to be calculated by multiplying the coefficients along the indirect path, $\beta_{\text {ind }}=-.05, p<.01 .^{7}$ Finally, the total effect of repetition frequency is obtained by subtracting the indirect from the direct effect, $\beta_{\text {tot }}$ $=.12, p=.09$. This shows that the negative indirect effect of repetition almost completely diminishes the positive direct effect.

Statistically, the findings constitute a suppression effect. Suppression means that a correlation which is initially absent is revealed after controlling for mediating variables (Conger, 1974). In our case there was no correlation between repetition frequency and statement credibility to be found when the indirect path was excluded from the structural equation model, $\beta=-.03, p=.67$. It is communicator trustworthiness that, in the end, explains a considerable part of variance with regard to statement credibility. The remaining unexplained variance is positively correlated with repetition frequency, which explains the significant path coefficient in the overall model. ${ }^{8}$

The suppression issue is worth of additional attention. We considered reactance as a key variable within the model. However, one could argue that reactance is not essential in terms of mediating the relationship between repetition and statement credibility, since participants might downgrade statement credibility simply because they would realize the communicator's intent to persuade. To test this alternative explanation, we computed two additional models. Within the first, we freed the path ranging from "perceived persuasive intent" to "statement credibility", $\beta=-.03, p=.68$, to account for a possible direct effect. In 
the second model, we added a path between "persuasive intent" and "communicator credibility", $\beta=-.11, p=.15$, to see whether participants' trust in the communicator decreases without them being reactant. In both models, the respective path coefficients were not statistically significant and model fit did not improve (model 1: $\chi^{2}=72.78, d f=49, p=.02$; $\mathrm{SRMR}=.08 ; \mathrm{RMSEA}=.05 ; \mathrm{CFI}=.98 ;$ model $2: \chi^{2}=70.72, d f=48, p=.02 ; \mathrm{SRMR}=.08 ;$ RMSEA $=.05 ; \mathrm{CFI}=.98$ ). These results underline the critical role of reactance within the mediating process.

\section{Discussion}

This study was motivated by earlier findings on the truth effect, suggesting that the credibility of a statement increases if it is repeated, but weakens or even reverses with more frequent repetition (Hawkins et al., 2001; Koch \& Zerback, 2012). We were able to replicate these findings and demonstrated that repetition indeed increases statement credibility. In addition, our study broadens the theoretical and empirical understanding of the truth effect by providing an explanation for its decline after a certain number of repetitions. Our analysis shows that an indirect effect, counteracting the truth effect, is triggered by frequent repetition. The key variable in this process is reactance, resulting from identifying repetition as a persuasive tactic. Contrary to previous studies, citing reactance ex post facto as a possible cause for the decline of statement credibility after frequent repetition, our study incorporates reactance as an analytical construct. Reactance is triggered by the perceived intent to persuade: Recipients imply that the communicator tries to persuade them. In keeping with J. W. Brehm (1966) that recipients will consider attempts at persuasion to be restrictions of their freedom, a perceived intent to persuade evokes reactance.

We also accounted for two potential consequences of reactance, namely on perceived statement credibility and on communicator credibility (Meirick \& Nisbett, 2011; Quick \& 
Bates, 2010). Contrary to our expectations, reactance does not directly decrease statement credibility, but yields an indirect effect by decreasing communicator credibility. This suggests that reactance, triggered by a recognized attempt at persuasion, can lead to differentiated cognitive assessments, as subjects do not necessarily devaluate both message and source.

\section{Limitations and implications}

The results presented are limited in various respects. The first aspect relates to the stimulus: The finding that reactance only affected communicator credibility might be due to the fact that within an interview the interviewee is in the focus of reader's attention and therefore held responsible for the frequent repetition. A second stimulus related limitation concerns the repetition density: while the triple repetition of a statement seems plausible in the context of a 600-word printed interview, repeating a statement five or seven times might be considered as rather artificial. Still, the stimulus has to be seen in light of the study's main goal, which was not to achieve external validity in terms of a realistic amount of repetitions, but to explain the truth effect's decline after a certain number of presentations. It was therefore necessary to successively increase frequency of statement exposure to a considerable level.

Furthermore, external validity is restricted because participants were aware of the experimental situation. Although we did not reveal the objective of the study, participants probably were still more attentive than in an everyday situation and thus more likely to notice attempts at persuasion. Regarding the degree of reactance, also the type of message might be relevant. One might assume e.g. that the correlation between perceived intent to persuade and reactance might be lower when people expect an attempt at persuasion (i.e., advertising) than when the persuasive intention is concealed.

It should also be mentioned that the model as such can prove causality only to a particular extent. Strictly speaking and according to experimental logic, only the two paths 
directly linked to our independent variable (presentation of the statement) can be interpreted in a causal manner, whereas causal interpretation of the other four relationships follows only from theoretical considerations.

Finally, there are certain limitations inherent to measuring reactance. While the 'creators' of reactance theory (Brehm \& Brehm, 1981, p. 37) conclude that the construct has the status of an intervening, hypothetical variable which cannot be measured directly (thus, the only way to assess the presence of reactance would be to infer it from its effects, e.g. by measuring attitudes or behavior), research now suggests "that it is possible to use a combination of self-report cognitive and emotional measures to create a more or less direct index of reactance" (Dillard \& Shen, 2005, p. 160). Dillard and Shen (2005, p. 162) also express implications for assessing reactance induced by persuasive messages and conclude that reactance can be measured using self-report techniques and that anger as well as negative cognitions should be assessed. The items we used in our study are taken from the "psychometric ambiguous reactance scale", developed by Herzberg (2002); it measures anger as well as negative cognitions, similar to the composite index of anger and negative cognitions developed by Dillard and Shen. Yet, we did not use the thought listing technique to measure cognitive responses and their four-step sequence coding. Thus, follow-up studies could solve this problem. Also our data solely relates to the reactance caused by the communicator. It may also be possible that the participants experienced reactance towards the journalist, who allows (or fails to prevent) such frequent repetition of the statement in the interview. These potential effects were not controlled for.

\section{Future research directions}

In addition to rectifying the problems discussed above, future studies could particularly address the influence of context factors on the observed negative effect of repetition frequency. This may include, for instance, the lapse of time between stimulus 
presentations. Thus, if a statement would be presented even more often, reactance might be weaker or set in later if more time passes between presentations. The extent to which counterarguments or counter-statements affect the truth effect has also not been addressed in previous studies. Many situations involving repetition of persuasive messages are characterized by counter-arguing or contradiction in general (as e.g. included in televised debates, discussion panels, interpersonal networks, or internet forums). The manner in which contradiction affects the truth effect may be a fruitful endeavor for future research. 


\section{References}

Arkes, H. R., Boehm, L., \& Xu, G. (1991). Determinants of judged validity. Journal of Experimental Social Psychology, 27(6), 576-605. doi: 10.1016/0022-1031(91)90026-3

Arkes, H. R., Hackett, C., \& Boehm, L. (1989). The generality of the relation between familiarity and judged validity. Journal of Behavioral Decision Making, 2(2), 81-94. doi: 10.1002/bdm.3960020203

Bacon, F. T. (1979). Credibility of repeated statements: Memory for trivia. Journal of Experimental Psychology: Human Learning and Memory, 5(3), 241-252. doi: 10.1037/0278-7393.5.3.241

Baseheart, J. R., \& Bostrom, R. N. (1972). Credibility of source and of self in attitude change. Journalism Quarterly, 49(4), 742-745. doi: 10.1177/107769907204900418

Begg, I., Anas, A., \& Farinacci, S. (1992). Dissociation of processes in belief: Source recollection, statement familiarity, and the illusion of truth. Journal of Experimental Psychology: General, 121(4), 446-458. doi: 10.1037/0096-3445.121.4.446

Begg, I., \& Armour, V. (1991). Repetition and the ring of truth: Biasing comments. Canadian Journal of Behavioural Science, 23(2), 195-213. doi: 10.1037/h0079004

Begg, I., Armour, V., \& Kerr, T. (1985). On believing what we remember. Canadian Journal of Behavioural Science, 17(3), 199-214. doi: 10.1037/h0080140

Berlo, D. K., Lemert, J. B., \& Mertz, R. J. (1969). Dimensions for evaluating the acceptability of message sources. Public Opinion Quarterly, 33(4), 563-576. doi: 10.1086/267745

Berlyne, D. E. (1970). Novelty, complexity, and hedonic value. Perception \& Psychophysics, 8(5), 279-286. doi: 10.3758/BF03212593

Berscheid, E. (1966). Opinion change and communicator-communicatee similarity and dissimilarity. Journal of Personality and Social Psychology, 4(6), 670-680. doi: $10.1037 / \mathrm{h} 0021193$ 
Boehm, L. E. (1994). The validity effect: A search for mediating variables. Personality and Social Psychology Bulletin, 20(3), 285-293. doi: 10.1177/0146167294203006

Bornstein, R. F. (1989). Exposure and affect: Overview and meta-analysis of research, 19681987. Psychological Bulletin, 106(2), 265-289. doi: 10.1037/0033-2909.106.2.265

Brehm, J. W. (1966). A Theory of Psychological Reactance. New York: Academic Press.

Brehm, J. W. (1972). Responses to loss of freedom: a theory of psychological reactance. Morristown, NJ: General Learning Press.

Brehm, S. S., \& Brehm, J. W. (1981). Psychological Reactance: A Theory of Freedom and Control. New York: Academic Press.

Brock, T. C. (1965). Communicator-recipient similarity and decision change. Journal of Personality and Social Psychology, 1(6), 650-654. doi: 10.1037/h0022081

Brown, A. S., \& Nix, L. A. (1996). Turning lies into truths: Referential validation of falsehoods. Journal of Experimental Psychology: Learning, Memory, and Cognition, 22(5), 1088-1100. doi: 10.1037/0278-7393.22.5.1088

Burgoon, M., Alvaro, E. M., Grandpre, J., \& Voulodakis, M. (2002). Revisiting the theory of psychological reactance: Communicating threats to attitudinal freedom. In J. P. Dillard \& M. Pfau (Eds.), The persuasion handbook. Developments in theory and practice (pp. 213-232). Thousand Oaks: Sage Publications.

Byrne, B. (2001). Structural equation modeling with AMOS. Basic concepts, applications and programming. Mahwah, NJ: Lawrence Erlbaum Associates.

Cacioppo, J. T., \& Petty, R. E. (1979). Effects of message repetition and position on cognitive responses, recall, and persuasion. Journal of Personality and Social Psychology, 37(1), 97-109. doi: 10.1037/0022-3514.37.1.97

Cacioppo, J. T., \& Petty, R. E. (1989). Effects of message repetition on argument processing, recall, and persuasion. Basic and Applied Social Psychology, 10(1), 3-12. doi: 10.1207/s15324834basp1001_2 
Campbell, M. C., \& Kirmani, A. (2000). Consumers' use of persuasion knowledge: The effects of accessibility and cognitive capacity on perceptions of an influence agent. Journal of Consumer Research, 27(1), 69-83. doi: 10.1086/314309

Cheung, G. W., \& Lau, R. S. (2008). Testing mediation and suppression effects of latent variables: Bootstrapping with structural equation models. Organizational Research Methods 11(2), 296-325. doi: 10.1177/1094428107300343

Conger, A. J. (1974). A revised definition for suppressor variables: A guide to their identification and interpretation. Educational and Psychological Measurement, 34(1), 35-46. doi: 10.1177/001316447403400105

Cowley, E., \& Barron, C. (2008). When product placement goes wrong: The effects of program liking and placement prominence. Journal of Advertising, 37(1), 89-98. doi: 10.2753/JOA0091-3367370107

Dechêne, A., Stahl, C., Hansen, J., \& Wänke, M. (2010). The truth about the truth: A metaanalytic review of the truth effect. Personality and Social Psychology Review, 14(2), 238-257. doi: 10.1177/1088868309352251

Dillard, J. P., \& Shen, L. (2005). On the nature of reactance and its role in persuasive health communication. Communication Monographs, 72(2), 144-168. doi: $10.1080 / 03637750500111815$

Elfron, B. (1979). Bootstrap methods. Another look at the jackknife. The Annals of Statistics, 7(1), 1-26. doi: 10.1214/aos/1176344552

Elfron, B. (1987). Better bootstrap confidence intervals. Journal of the American Statistical Association, 82(397), 171-185. doi: 10.1080/02331889508802498

Fink, E. L., \& Cai, D. A. (2013). Discrepancy models of belief change. In J. P. Dillard \& M. Pfau (Eds.), The persuasion handbook. Developments in theory and practice (pp. 84103). Thousand Oaks: Sage Publications. 
Friestad, M., \& Wright, P. (1994). The Persuasion Knowledge Model: How people cope with persuasion attempts. Journal of Consumer Research, 21(1), 1-31. doi: 10.1086/209380

Giffin, K. (1967). The contribution of studies of source credibility to a theory of interpersonal trust in the communication process. Psychological Bulletin, 68(2), 104-120. doi: $10.1037 / \mathrm{h} 0024833$

Gigerenzer, G. (1984). External validity of laboratory experiments: The frequency-validity relationship. American Journal of Psychology, 97(2), 185-195. doi: 10.2307/1422594

Grandpre, J., Alvaro, E. M., Burgoon, M., Miller, C. H., \& Hall, J. R. (2003). Adolescent reactance and anti-smoking campaigns: A theoretical approach. Health Communication, 15(3), 349-366. doi: 10.1207/S15327027HC1503_6

Hasher, L., Goldstein, D., \& Toppino, T. (1977). Frequency and the conference of referential validity. Journal of Verbal Learning and Verbal Behavior, 16(1), 107-112. doi: $10.1016 / \mathrm{S} 0022-5371(77) 80012-1$

Hawkins, S. A., \& Hoch, S. J. (1992). Low-involvement learning: Memory without evaluation. Journal of Consumer Research, 19(2), 212-225. doi: 10.1086/209297

Hawkins, S. A., Hoch, S. J., \& Meyers-Levy, J. (2001). Low-involvement learning: Repetition and coherence in familiarity and belief. Journal of Consumer Psychology, 11(1), 1-11. doi: 10.1207/S15327663JCP1101_1

Herzberg, P. Y. (2002). Zur psychometrischen Optimierung einer Reaktanzskala mittels klassischer und IRT-basierter Analysemethoden. Diagnostica, 48(4), 163-171. doi: $10.1026 / / 0012-1924.48 .4 .163$

Holbert, R. L., \& Stephenson, M. T. (2002). Structural equation modeling in the communication sciences, 1995-2000. Human Communication Research, 28(4), 531551. doi: 10.1111/j.1468-2958.2002.tb00822.x

Holbert, R. L., \& Stephenson, M. T. (2003). The importance of indirect effects in media effects research. Testing for mediation in structural equation modeling. Journal of 
Broadcasting \& Electronic Media, 47(4), 556-572. doi:

10.1207/s15506878jobem4704_5

Horai, J., Naccari, N., \& Fatoullah, E. (1974). The effects of expertise and physical attractiveness upon opinion agreement and liking. Sociometry, 37(4), 601-606. doi: $10.2307 / 2786431$

Hovland, C. I., Janis, I. L., \& Kelley, H. H. (1953). Communication and persuasion. Psychological studies of opinion change. New Haven, CT: Yale University Press.

Hovland, C. I., \& Weiss, W. (1951). The influence of source credibility on communication effectiveness. Public Opinion Quartertly, 15(4), 635-650. doi: 10.1086/266350

Hu, L.-t., \& Bentler, P. M. (1999). Cutoff criteria for fit indexes in covariance structure analysis: Conventional criteria versus new alternatives. Structural Equation Modeling: A Multidisciplinary Journal, 6(1), 1-55. doi: 10.1080/10705519909540118

Johar, G. V., \& Roggeveen, A. L. (2007). Changing false beliefs from repeated advertising: The role of claim-refutation alignment. Journal of Consumer Psychology, 17(2), 118127. doi: 10.1016/S1057-7408(07)70018-9

Kaplowitz, S. A. , Fink, E. L., Armstrong, G. B., \& Bauer, C. L. (1986). Message discrepancy and the persistence of attitude change: Implications of an information-integration model. Journal of Experimental Social Psychology, 22, 507-530. doi: 10.1016/00221031(86)90048-X

Koch, T., \& Zerback, T. (2012). Repetition and truth. How repeated political slogans affect judgments of credibility. Paper presented at the 62nd Annual Conference of the International Communication Association, Phoenix, AZ.

Kohn, P. M., \& Barnes, G. E. (1977). Subject variables and reactance to persuasive communications about drugs. European Journal of Social Psychology, 7(1), 97-109. doi: 10.1002/ejsp.2420070108 
LaVail, K. H., Anker, A. E., Reinhart, A., \& Feeley, T. H. (2010). The persuasive effects of audiovisual PSAs to promote organ donation: The mediating role of psychological reactance. Communication Studies, 61(1), 46-69. doi:10.1080/10510970903400337

MacKinnon, D. P., Lockwood, C. M., \& Williams, J. (2004). Confidence limits for the indirect effect. Distribution of the product and resampling methods. Multivariate Behavioral Research, 39(1), 99-128. doi: 10.1207/s15327906mbr3901_4

Matthes, J., Schemer, C., \& Wirth, W. (2007). More than meets the eye: Investigating the hidden impact of brand placements in television magazines. International Journal of Advertising, 26(4), 477-503.

McGuire, W. J., \& Papageorgis, D. (1962). Effectiveness of forewarning in developing resistance to persuasion. Public Opinion Quarterly, 26(1), 24-34. doi: 10.1086/267068

Meirick, P. C., \& Nisbett, G. S. (2011). I approve this message: Effects of sponsorship, ad tone, and reactance in 2008 presidential advertising. Mass Communication and Society, 14(5), 666-689. doi: 10.1080/15205436.2010.530381

Miller, C. H., Lane, L. T., Deatrick, L. M., Young, A. M., \& Potts, K. A. (2007). Psychological reactance and promotional health messages: The effects of controlling language, lexical concreteness, and the restoration of freedom. Human Communication Research, 33(2), 219-240. doi: 10.1111/j.1468-2958.2007.00297.x

Miller, R. L. (1976). Mere exposure, psychological reactance, and attitude change. Public Opinion Quarterly, 40(2), 229-233. doi: 10.1086/268290

Moyer-Gusé, E., \& Nabi, R. L. (2010). Explaining the effects of narrative in an entertainment television program: overcoming resistance to persuasion. Human Communication Research, 36(1), 26-52. doi: 10.1111/j.1468-2958.2009.01367.x

Moyer-Gusé, E., Jain, P., \& Chung, A. H. (2012). Reinforcement or reactance? Examining the effect of an explicit persuasive appeal following an entertainment-education narrative. Journal of Communication, 62(6), 1010-1027. doi:10.1111/j.1460-2466.2012.01680.x 
O'Keefe, D. J. (2002). Persuasion: Theory and Research. Thousand Oaks, CA: Sage.

Parks, C. M., \& Toth, J. P. (2006). Fluency, familiarity, aging, and the illusion of truth. Aging, Neuropsychology, and Cognition, 13(2), 225-253. doi: 10.1080/138255890968691

Patzer, G. L. (1983). Source credibility as a function of communicator physical attractiveness. Journal of Business Research, 11(2), 229-241. doi: 10.1016/0148-2963(83)90030-9

Petty, R. E., \& Cacioppo, J. T. (1977). Forewarning, cognitive responding, and resistance to persuasion. Journal of Personality and Social Psychology, 35(9), 645-655. doi: $10.1037 / 0022-3514.35 .9 .645$

Quick, B. L., \& Bates, B. R. (2010). The use of gain- or loss-frame messages and efficacy appeals to dissuade excessive alcohol consumption among college students: a test of psychological reactance theory. Journal of Health Communication, 15(6), 603-628. doi: $10.1080 / 10810730.2010 .499593$

Reber, R., \& Schwarz, N. (1999). Effects of perceptual fluency on judgments of truth. Consciousness and Cognition, 8(3), 338-342. doi: 10.1006/ccog.1999.0386

Reber, R., Winkielman, P., \& Schwarz, N. (1998). Effects of perceptual fluency on affective judgments. Psychological Science, 9(1), 45-48. doi: 10.1111/1467-9280.00008

Reinhart, A. M., Marshall, H. M., Feeley, T. H., \& Tutzauer, F. (2007). The persuasive effects of message framing in organ donation: The mediating role of psychological reactance. Communication Monographs, 74(2), 229-255. doi: 10.1080/03637750701397098

Roggeveen, A. L., \& Johar, G. V. (2002). Perceived source variability versus familiarity: Testing competing explanations for the truth effect. Journal of Consumer Psychology, 12(2), 81-91. doi: 10.1207/S15327663JCP1202_02

Saegert, S. C., \& Jellison, J. M. (1970). Effects of initial level of response competition and frequency of exposure on liking and exploratory behavior. Journal of Personality and Social Psychology, 16(3), 553-558. doi: 10.1037/h0029952 
Schemer, C., Matthes, J., Wirth, W., \& Textor, S. (2008). Does 'passing the courvoisier' always pay off? Positive and negative evaluative conditioning effects of brand placements in rap videos. Psychology \& Marketing, 25(10), 923-943. doi: 10.1002/mar.20246

Schumacker, R. E., \& Lomax, R. G. (2004). A beginners guide to structural equation modeling. Mahwah, NJ: Lawrence Erlbaum Associates.

Schwartz, M. (1982). Repetition and rated truth value of statements. American Journal of Psychology, 95(3), 393-407. doi: 10.2307/1422132

Seamon, J. G., Williams, P. C., Crowley, M. J., Kim, I. J., Langer, S. A., Orne, P. J., \& Wishengrad, D. L. (1995). The mere exposure effect is based on implicit memory: Effects of stimulus type, encoding conditions, and number of exposures on recognition and affect judgments. Journal of Experimental Psychology: Learning, Memory, and Cognition, 21(3), 711-721. doi: 10.1037/0278-7393.21.3.711

Smith, M. J. (1977). The effects of threats to attitudinal freedom as a function of message quality and initial receiver attitude. Communication Monographs, 44(3), 196-206. doi: $10.1080 / 03637757709390131$

Snyder, M., \& Rothbart, M. (1971). Communicator attractiveness and opinion change. Canadian Journal of Behavioral Science, 3, 377-387. doi: 10.1037/h0082280

Stephenson, M. T., \& Holbert, R. L. (2003). A monte carlo simulation of observable versus latent variable structural equation modeling techniques. Communication Research, 30(3), 332-354. doi:10.1177/0093650203030003004

Unkelbach, C. (2007). Reversing the truth effect: Learning the interpretation of processing fluency in judgments of truth. Journal of Experimental Psychology: Learning, Memory, and Cognition, 33(1), 219-230. doi: 10.1037/0278-7393.33.1.219 
Unkelbach, C., Bayer, M., Alves, H., Koch, A., \& Stahl, C. (2011). Fluency and positivity as possible causes of the truth effect. Consciousness and Cognition, 20(3), 594-602. doi: 10.1016/j.concog.2010.09.015

Westland, J.C. (2010). Lower bounds on sample size in structural equation modeling. Electronic commerce research and applications, 9(6), 476-487. doi: 10.1016/j.elerap.2010.07.003

Whitehead, J. L. (1968). Factors of source credibility. Quarterly Journal of Speech, 54(1), 5963. doi: 10.1080/00335636809382870

Wicklund, R. A. (1974). Freedom and Reactance. Potomac, MD: Lawrence Erlbaum Associates.

Williams, P., Fitzsimons, G. J., \& Block, L. G. (2004). When consumers do not recognize 'benign' intention questions as persuasion attempts. Journal of Consumer Research, 31(3), 540-550. doi: 10.1086/425088

Worchel, S., \& Brehm, J. W. (1970). Effect of threats to attitudinal freedom as a function of agreement with the communicator. Journal of Personality and Social Psychology, 14(1), 18-22. doi: 10.1037/h0028620

Yung, Y.-F., \& Bentler, P. M. (2003). Bootstrapping techniques in analysis of mean and covariance structures. In G. A. Marcoulides \& R. E. Schumacker (Eds.), Advanced structural equation modeling. Issues and techniques (pp. 195-226). Mahwah, NJ: Lawrence Erlbaum Associates.

Zajonc, R. B. (1968). Attitudinal effects of mere exposure. Journal of Personality and Social Psychology, 9(2), 1-27. doi: 10.1037/h0025848

Zajonc, R. B., Crandall, R., Kail, R. V., \& Swap, W. (1974). Effect of extreme exposure frequencies on different affective ratings of stimuli. Perceptual and Motor Skills, 38 (2), 667-678. doi: 10.2466/pms.1974.38.2.667 


\section{Footnotes}

${ }^{1}$ These findings, however, remain fairly descriptive, as the authors do not report the significance between individual measurements but only the significance of the main effect.

${ }^{2}$ In addition to these dimensions, research on source credibility has also pointed to further dimensions, for example, attractiveness, perceived similarity between recipient and communicator, dynamism, sympathy, and social acceptance (Baseheart \& Bostrom, 1972; Berlo, Lemert, \& Mertz, 1969; Berscheid, 1966; Brock, 1965; Giffin, 1967; Horai, Naccari, \& Fatoullah, 1974; Patzer, 1983; Snyder \& Rothbart, 1971; Whitehead, 1968). However, these are only of importance when no other information about a source is available, and are best considered as reinforcers (O'Keefe, 2002, pp. 181-191). Expertise and trustworthiness, on the other hand, are the only dimensions found in nearly all analyses.

${ }^{3}$ In confirmatory factor analyses, constructs are presented within structural equation models, taking means measurement errors into account. In this way, the quality of the analysis is further increased.

${ }^{4}$ The minimum sample size required for a study using a structural equation model depends on the number of observed and latent variables, the desired probability and statistical power levels, and the anticipated effect size. We used an algorithm developed by Westland (2010, pp. 481-482) to compute the minimum sample size required. According to this algorithm and accounting for the structural complexity of our model, the recommended minimum sample size is 100 participants.

${ }^{5}$ The conclusions inferred to within the scope from the structural equation model are based on the assumption of multiple normally distributed variables (Schumacker \& Lomax, 2004, p. 11); this assumption is usually (and also in the case of this study) violated. The bootstrap procedure represents a conventional way of dealing with the violation of this premise. It refers 
to a re-sampling method in which a large number of random samples (here: 10.000) is drawn from the original sample (Elfron, 1979, 1987). In this respect, the sample in this study must be considered a quasi-population from which the random sample $N$ is drawn. The distribution of various population parameters created this way provides considerably more reliable confidence intervals than other, conventional significance tests (Byrne, 2001, pp. 267-286; Yung \& Bentler, 2003).

${ }^{6}$ Measurement models using only two manifest indicators are underidentified, meaning that the information provided by the data is not sufficient to estimate model parameters. A possible solution for this problem is to simply use an index consisting of the two indicators as a substitute for the latent variable. However, that way a major advantage of structural equation modeling is lost - namely the possibility to account for measurement errors. We therefore followed an alternative approach offered and tested by Stephenson and Holbert (2003) called Latent Composite Structural Equation Modeling. It allows researchers to use latent variables consisting of only one manifest indicator which itself is an index of two or more manifest variables. Mathematically the path from the latent construct to the observed variable is fixed to 1.0 and the error variance of the observed index is fixed to ( 1 - reliability) x indicator variance. In a monte carlo simulation Stephenson and Holbert (2003) showed that LC models yielded parameter estimates that were more reliable than those in models using only observed variables (pp. 335-336).

${ }^{7}$ Multiplying the coefficients of the indirect effect does, however, lead to the corresponding product being normally distributed only in exceptional cases. As a consequence, conventional significance tests that require a normal distribution of the data in question can lead to distorted results. For this reason, a corrected bootstrap technique (BC bootstrap), which is adjusted for such distortions, is employed in this study (Cheung \& Lau, 2008; Holbert \& Stephenson, 2003; MacKinnon, Lockwood, \& Williams, 2004). 
${ }^{8} \mathrm{We}$ also checked whether the missing correlation between repetition and statement credibility in the simple bivariate model is due to a non-linear character of this relationship (inverted U). To do so, we added a quadratic term to this model (repetition ${ }^{2}$ ) as an independent variable. If the relationship follows an inverted $U$, one would expect the quadratic term to have a significant negative regression coefficient - which was the case $(\beta=$ $-.64, p<.05)$. Model fit: $\chi^{2}=2.75, \mathrm{df}=4, \mathrm{p}=.60 ;$ SRMR $=.02 ; \mathrm{RMSEA}=.00 ; \mathrm{CFI}=1.00$ 


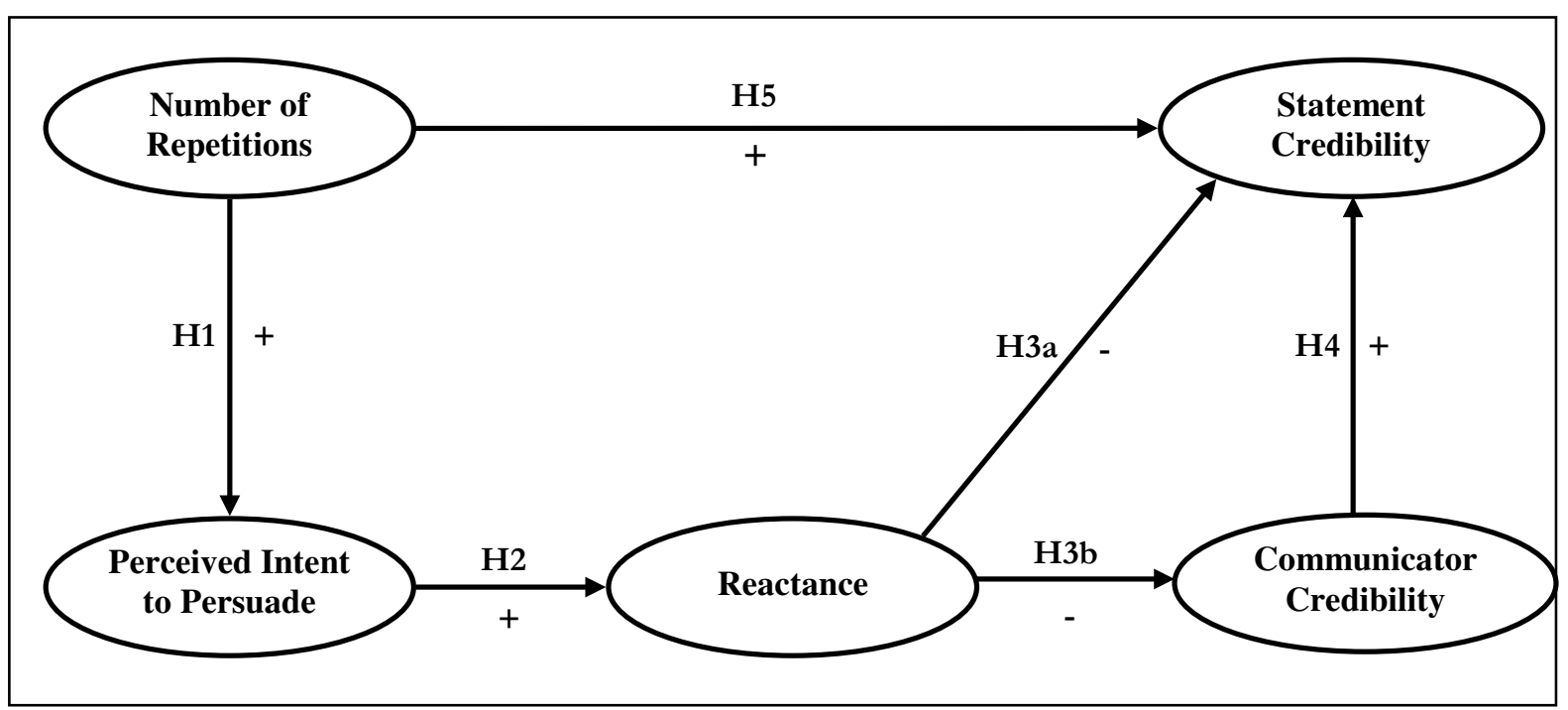

Figure 1

Theoretically postulated relationships between statement repetition frequency and statement credibility 
Table 1

Zero-Order Correlations

\begin{tabular}{lccccc}
\hline & 1 & 2 & 3 & 4 & 5 \\
\hline 1. Number of presentations & - & & & & \\
2. Statement credibility & -.03 & - & & & \\
3. Perceived intent to persuade & $.25^{* *}$ & $-.16^{*}$ & - & & \\
4. Reactance & $.36^{* *}$ & $-.35^{* *}$ & $.30^{* *}$ & - & \\
5. Communicator credibility & $-.34^{* *}$ & $.48^{* *}$ & $-.28^{* *}$ & $-.61^{* *}$ & - \\
\hline
\end{tabular}

${ }^{* *} p<.01 ; * p<.05$ 


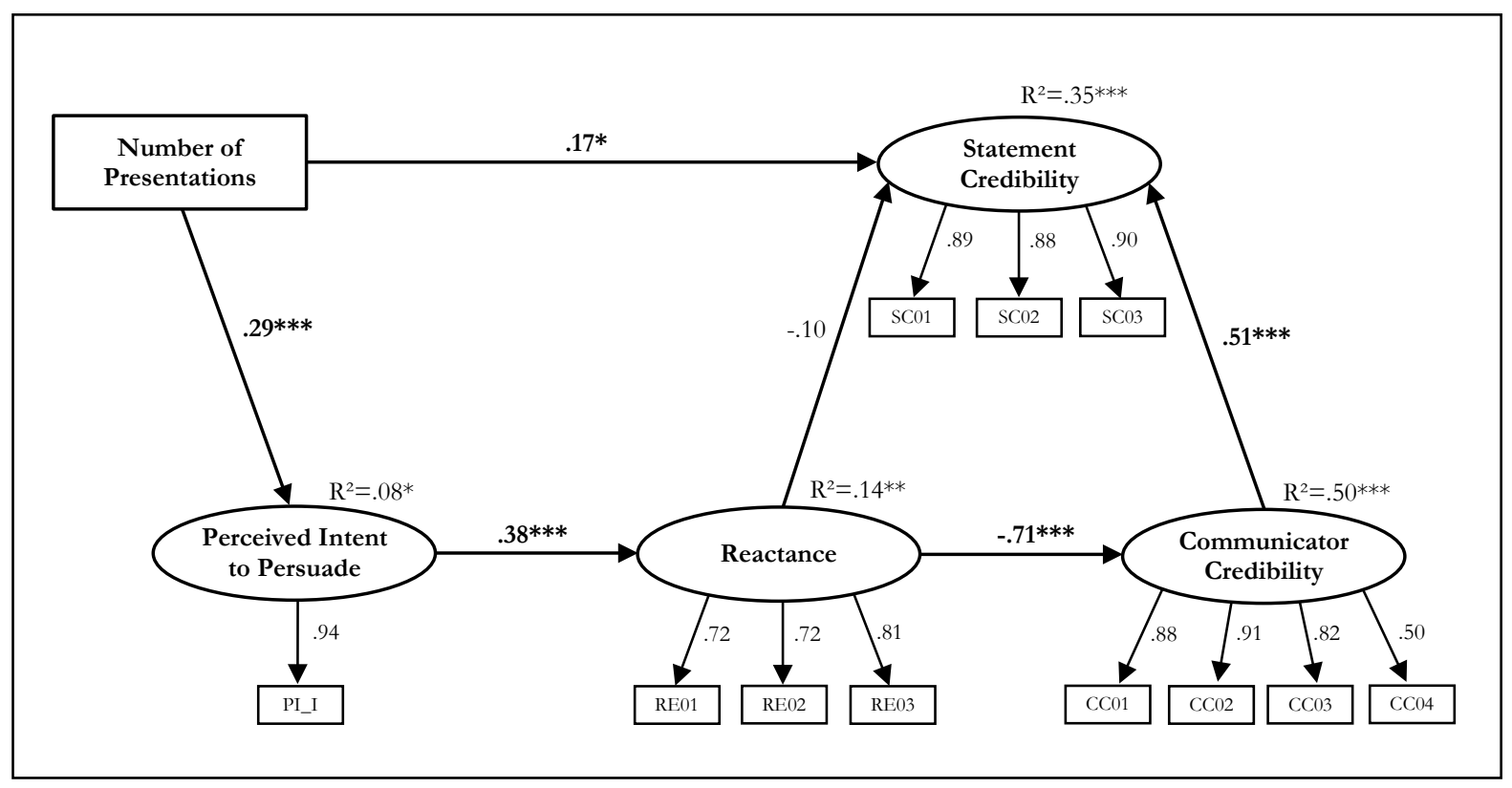

Figure 2 Observed Structural Equation Model $* * * p<.001 ; * * p<.01$

Note. All significance tests were calculated by means of bootstrapping (10.000 samples). The confidence intervals of the indirect effects are corrected for distortions that could arise from the multiplication of path coefficients. 